\title{
Balkanologie
}

Balkanologie Revue d'études pluridisciplinaires

Vol. II, nº 1 | 1998

Volume II Numéro 1

\section{Les principautés roumaines de Valachie et de Moldavie et leur environnement slavo-byzantin}

Benoît Joudiou

\section{(2) OpenEdition}

\section{Journals}

Édition électronique

URL : http://journals.openedition.org/balkanologie/241

DOI : 10.4000/balkanologie.241

ISSN : 1965-0582

Éditeur

Association française d'études sur les Balkans (Afebalk)

Édition imprimée

Date de publication : 1 juillet 1998

ISSN : 1279-7952

\section{Référence électronique}

Benoît Joudiou, « Les principautés roumaines de Valachie et de Moldavie et leur environnement slavobyzantin », Balkanologie [En ligne], Vol. II, n 1 | 1998, mis en ligne le 02 juin 2008, consulté le 17 décembre 2020. URL : http://journals.openedition.org/balkanologie/241 ; DOI : https://doi.org/ 10.4000/balkanologie.241

Ce document a été généré automatiquement le 17 décembre 2020.

(c) Tous droits réservés 


\title{
Les principautés roumaines de Valachie et de Moldavie et leur environnement slavo-byzantin
}

\author{
Benoît Joudiou
}

1 Les Roumains ne constituèrent des États qu'à partir du XIV ème siècle, avec la création des principautés de Valachie puis de Moldavie. Dès le début de leur histoire étatique, ils furent au contact des traditions culturelles et politiques plus anciennes des pays voisins. Situés aux confins de l'Europe centrale, ils étaient au carrefour d'influences diverses : byzantine tout d'abord, grâce à la présence de l'Empire au cours des siècles sur le Bas-Danube ${ }^{1}$, puis par l'intermédiaire des Slaves du Sud, occidentale également, par la Hongrie et la Pologne voisines.

Cependant, l'appartenance des Roumains à la chrétienté orthodoxe privilégia plutôt des relations avec la culture byzantine. L'héritage culturel et les traditions politiques qu'ils reçurent du monde slavo-byzantin contribuèrent à la naissance d'une culture originale, participant pleinement à la civilisation médiévale de l'Europe du sud-est. En effet, l'identité politique et culturelle de la Valachie et de la Moldavie n'apparaît dans toute son intégrité qu'à l'issue d'un processus d'acculturation, dont témoignent particulièrement la littérature slavo-roumaine et la tradition souveraine. Il n'est pas question d'insister ici sur les origines et le développement des relations culturelles et politiques entre les Roumains et leurs voisins du sud, des Slaves fortement influencés par Byzance ${ }^{2}$. Plus modestement, nous avons cherché à dégager quelques aspects durables dans ces relations, d'un intérêt évident tant pour la civilisation roumaine médiévale que pour le devenir du monde post-byzantin en Europe du sud-est.

C'est une période d'affirmation culturelle des principautés, entre le milieu du XV ème siècle et les années 1520 , qui nous semble propice pour esquisser un bilan, non pas exhaustif, mais précisant la place des pays roumains dans le partage culturel de l'Europe orientale ${ }^{3}$. En Moldavie, le règne du prince Étienne le Grand (1457-1504) couvre presque toute la période pendant laquelle cette principauté à l'est des Carpates s'affirma comme une puissance régionale non négligeable : ce prince affronta ses deux 
puissants voisins catholiques, la Hongrie puis la Pologne, ainsi que les Ottomans, avec des résultats plus ou moins heureux. Sur le plan culturel, le règne inaugure l'âge d'or de l'art moldave qui devait encore s'épanouir au cours du siècle suivant et voit naître les premières chroniques, composées à la cour princière.

La Valachie, située au sud-est des Carpates, était alors directement voisine de l'Empire ottoman. L'instabilité politique qui régna jusqu'aux dernières décennies du XV ${ }^{\text {ème }}$ siècle rend difficile une comparaison avec la Moldavie: le pays fut souvent un champ de bataille entre différents prétendants, avec des interventions hongroises, ottomanes et moldaves. À la fin du siècle et au début du suivant, la paix revint peu à peu, permettant un essor culturel remarquable, en particulier sous les règnes des princes Radu le Grand (1495-1508) et Neagoe Basarab (1512-1521). C'est à la cour de ce dernier, ou du moins sous son influence, que furent rédigées les premières oeuvres littéraires de Valachie.

\section{Un héritage culturel lié à l'orthodoxie}

5 La culture roumaine écrite d'expression slavonne est apparue au cours de la seconde moitié du XIVème siècle, c'est-à-dire pendant les décennies de construction des deux principautés. Son développement initial fut favorisé par celui de l'administration princière (les premiers actes émis par les chancelleries princières qui nous sont parvenus datent de la seconde moitié du XIV ème siècle), mais aussi par l'Église, qui utilisait une liturgie slavonne. En effet, parallèlement aux structures politiques se mit alors en place une organisation ecclésiastique, avec la reconnaissance par le patriarcat de Constantinople de deux métropoles, l'une en Valachie (puis deux pendant quelques décennies), l'autre en Moldavie. C'est aussi à la fin du XIVème siècle et au début du XVème que furent créés les premiers monastères, connus par les donations qu'ils reçurent des souverains roumains ou étrangers, mais aussi par l'activité de leurs scriptoria.

6 La plupart des manuscrits copiés dans les pays roumains aux XV-XVI ${ }^{2}$ èe siècles appartenaient principalement à la littérature liturgique ou homilétique ${ }^{4}$. D'autre part, des romans populaires parvinrent à la même époque dans les pays roumains, notamment par l'intermédiaire des Slaves balkaniques. Ils contiennent souvent une morale religieuse, soit sous la forme d'écrits apocryphes (par exemple le Voyage de la Mère de Dieu aux Enfers), soit par la transposition chrétienne d'anciens livres de sagesse orientale, tel l'ancien roman byzantin Barlaam et Josaphat. De courts extraits de ce dernier figurent dans les Enseignements du prince valaque Neagoe Basarab à son fils Théodose, une oeuvre politique majeure du Moyen Age roumain, rédigée vers $1520^{5}$.

7 La circulation des textes slavo-byzantins rendait les principautés particulièrement réceptives aux grands courants spirituels de l'Europe du sud-est. Ainsi, la Valachie et la Moldavie aux XIV-XVI ${ }^{\text {ème }}$ siècles ont été influencées par l'hésychasme. Ce mouvement spirituel né dans l'Église byzantine au XIVème siècle fut aussi accompagné d'une intense activité culturelle, notamment en Bulgarie, sous le double patronage du patriarche Euthyme de Trnovo et du tsar Jean Alexandre (1331-1371)6. Fortement implanté dans les monastères du Mont Athos, l'hésychasme se répandit dans les communautés monastiques bulgares qui devinrent les grands centres hésychastes des Balkans.

8 Sa pénétration dans les pays roumains est liée à l'influence bulgare (par les relations entre le patriarche Euthyme et le moine Nicodème de Tismana en Valachie au début du $\mathrm{XV}^{\text {ème }}$ siècle), mais aussi à l'influence directe de l'Athos, qui forma Nicodème ou encore l'ex-patriarche de Constantinople Niphon II, exilé en Valachie au début du XVI ème 
siècle. L'érémitisme gagna également les pays roumains, sans devenir toutefois une pratique dominante. On peut du moins relier à l'influence hésychaste certains lieux de méditation (schituri), par exemple ceux des monts de Buzău en Valachie, qui reçurent des donations du prince Neagoe Basarab ${ }^{7}$.

Par ailleurs, dans les Enseignements de Neagoe Basarab à son fils Théodose règne une rigoureuse spiritualité monastique; l'importance de ces passages ascétiques a même fait douter quelques historiens roumains de la paternité princière de l'oeuvre ${ }^{8}$. Il existe cependant d'autres écrits de cette nature, imprégnés eux aussi d'un esprit ascétique, tels les conseils du grand-prince de Kiev Vladimir Monomaque à ses fils au XII ${ }^{\text {ème }}$ siècle ${ }^{9}$. Au-delà de l'ouvrage parénétique, destiné à l'éducation du jeune prince, les Enseignements reposent sur la puissance rédemptrice de la prière et du repentir, avec une force toute particulière qui semble due au courant hésychaste. Les hésychastes avaient remis au goût du jour les théologiens de l'époque patristique (Jean Chrysostome), protobyzantine (Ephrem le Syrien) et byzantine (Siméon le Moine) qui préconisaient l'ascétisme, notamment dans des sermons adressés aux moines. Ce sont ces mêmes sermons qui constituent les sources des passages ascétiques des Enseignements, et cela ne doit pas nous surprendre: les recommandations de dépouillement signifient que le prince doit se méfier des attraits de "ce vain monde"; rappelons à ce propos que l'idéal monastique incarnait les plus hautes vertus chrétiennes.

10 L'attrait du monastère n'était d'ailleurs pas plus étranger aux familles princières roumaines qu'il ne l'avait été pour les basileis byzantins ${ }^{10}$. L'oncle de Neagoe Basarab, le grand ban Barbu de Craiova renonça, à la fin de sa vie en 1520, à sa haute dignité pour revêtir la robe monastique. Comme d'autres princesses devenues veuves, Despina, l'épouse serbe de Neagoe, se retira dans un monastère après la mort du voiévode. Plus tard, en 1568, le prince de Moldavie Alexandre Lăpuşneanu confia le trône à son fils afin de mourir sous l'habit monacal, comme en témoigne le chroniqueur Azarias : «les choses de l'avenir lui ont davantage plu que celles qui sont immédiates et, au lieu de la pourpre brodée d'or, il a revêtu le vêtement de laine monacal $»^{11}$. À l'approche de la mort, le voiévode éprouva un besoin de "fuite du monde" qui nous semble proche à certains égards de l'esprit des Enseignements. Certes, il s'agit d'un exemple plus tardif, mais les continuités l'emportent dans la littérature historique roumaine des XV et $\mathrm{XVI}^{\mathrm{ème}}$ siècles $^{12}$.

11 Ces quelques aspects montrent combien il est difficile de comprendre la culture roumaine médiévale indépendamment de son environnement slavo-byzantin. Même si des liens politiques et économiques importants ont également existé avec l'Occident chrétien, surtout avec les royaumes voisins de Hongrie (puis avec la principauté de Transylvanie) et de Pologne, la culture roumaine prise au sens large (littérature religieuse, politique et historique, architecture, iconographie, etc.) révèle une synthèse avec des caractéristiques originales, nourries d'apports slavo-byzantins. Si les manuscrits copiés en grec sont très rares, c'est parce que cet héritage culturel a été transmis aux Roumains principalement par les slaves balkaniques. La voie de transmission bulgare est connue, notamment les liens entre le centre religieux et culturel de Trnovo et la Valachie voisine, liens qui ont duré jusqu'à la conquête de la Bulgarie par les Ottomans, c'est-à-dire jusqu'à la chute de Trnovo en 1393 et de Vidin en 1396. De nombreux manuscrits copiés au XV et XVI ${ }^{2}$ èe siècles dans les deux principautés avaient une origine bulgare ${ }^{13}$. C'est le cas notamment pour des oeuvres 
byzantines traduites en slave (Barlaam et Josaphat) comme pour des oeuvres originales, notamment les Vies de saints bulgares qui ont circulé aussi au nord du Danube (Vie de Saint Jean de Rila et de Sainte Philothée de Trnovo, écrites par le patriarche Euthyme). Il n'est plus possible de suivre le devenir de cette influence bulgare après la fin du XIVème siècle, au-delà de l'activité de l'higoumène Nicodème de Tismana en Valachie, qui eut, au moins, des relations épistolaires avec le patriarche Euthyme ${ }^{14}$. Les conséquences de la défaite bulgare furent terribles, les élites s'enfuirent (comme le patriarche Euthyme, qui mourut en exil) ou furent réduites au silence.

Malgré les conséquences des défaites serbes de 1371 et 1389, les liens religieux et culturels furent importants au XV ${ }^{\text {ème }}$ siècle avec les Roumains ${ }^{15}$. Le patriarche serbe d'Ipek (Peć) intronisa le métropolite moldave Théoctiste au milieu du XV ${ }^{\text {ème }}$ siècle, signe que les relations entre les Églises roumaines et Constantinople étaient distendues à l'époque de la conquête de la ville. D'autre part, une partie des élites serbes a pu trouver refuge en Valachie après la disparition du dernier despotat en 1459. Maxime Branković, qui appartenait à une famille de despotes, devint même métropolite de Valachie au début du XVI ${ }^{\text {ème }}$ siècle et sa nièce, Despina, épousa le futur voiévode Neagoe Basarab. Ce mariage perpétuait une tradition d'alliances entre les dynastes roumains, bulgares et serbes depuis le milieu du XIV ${ }^{\text {ème }}$ siècle. C'est aussi en partie sous le règne de Neagoe que le moine monténégrin Macaire, pour la première fois dans les pays roumains (et à une époque assez précoce pour l'Europe orientale : 1508-1512), imprima grâce au patronage princier des livres religieux en langue slavonne.

L'héritage byzantin dans les pays roumains est essentiellement lié à l'orthodoxie. C'est elle qui a maintenu les liens entre les Roumains et l'hellénisme post-byzantin, qu'un grand historien roumain, Nicolae Iorga, étudia notamment dans sa thèse Byzance après Byzance $^{16}$. Après la disparition des empereurs grecs, l'Église est demeurée l'héritière de Byzance, qu'il s'agisse du patriarcat oecuménique, qui reçut de Mahomet II un statut privilégié, ou de l'Athos, dont l'autonomie fut reconnue ${ }^{17}$. Les liens entre les Églises roumaines et le patriarcat sont anciens: les pays roumains étaient entrés dans la "famille d'État byzantine" d'abord avec la reconnaissance par Constantinople de leur siège métropolitain au XIV ${ }^{\text {ème }}$ siècle (Valachie) et au début du XV ${ }^{\text {ème }}$ siècle (Moldavie). $\mathrm{Au}$ début $\mathrm{du} \mathrm{XVI}^{\mathrm{ème}}$ siècle, ils ont retrouvé toute leur importance, comme en témoignent des visites de patriarches, à la recherche d'un soutien financier, par exemple en Valachie en $1517^{18}$.

14 Les patriarches, comme d'autres hiérarques grecs, savaient qu'ils pouvaient compter sur la "générosité" des voiévodes roumains. Demeurés après 1460 les derniers monarques orthodoxes de l'Europe du sud-est, les princes poursuivirent leurs donations à diverses communautés, pratique initiée dès le XIV ème siècle, en imitant le patronage des souverains bulgares et serbes. La sultane Mara (de la famille serbe des Branković), veuve de Murad II, adopta symboliquement le voiévode valaque Vlad le Moine et lui confia en 1492 la protection et l'entretien du monastère serbe de Chilandar, lui transmettant ainsi le droit de fondation ${ }^{19}$. Il faut souligner l'importance des donations de certains princes, ainsi qu'une certaine amplitude géographique, notamment sous les règnes d'Étienne le Grand en Moldavie, de Radu le Grand et de Neagoe Basarab en Valachie ${ }^{20}$. Ce dernier apparaît même comme "le donateur (ktitor) de toute la Sainte Montagne" (l'Athos) sous la plume de Gabriel le prôtos, supérieur général de l'Athos ${ }^{21}$. Le patronage des princes roumains a favorisé les échanges culturels, non seulement avec des monastères grecs, mais aussi avec ceux qui étaient occupés par des 
moines serbes et bulgares (Chilandar, Zographou, sans oublier Kutlumus, considérée alors comme la "Laure de la Valachie").

Les relations entre la Valachie et l'Église post-byzantine furent encore plus étroites pendant le séjour de l'ex-patriarche oecuménique Niphon II ; formé à l'Athos, il occupa à deux reprises le siège patriarcal de Constantinople. Vers 1503, alors qu'il a été destitué, nous le rencontrons en Valachie, invité par le prince Radu le Grand. Nous savons qu'il convoqua un synode local pour réorganiser l'Église valaque, mais il a aussi probablement laissé une empreinte culturelle dans la principauté. La Vie de Niphon, hagiographie rédigée par le prôtos Gabriel, du moins la version destinée à magnifier le règne de Neagoe Basarab, lui attribue un rôle de guide spirituel du futur prince, qui n'occupait alors qu'une fonction secondaire bien qu'il appartînt à la grande famille des bans de Craiova ${ }^{22}$. Canonisé après sa mort, il a été particulièrement vénéré par l'Église valaque, comme en témoigne la somptueuse cérémonie d'accueil de ses reliques par Neagoe $^{23}$.

\section{L'historiographie slavo-roumaine : synthèse culturelle et identité orthodoxe}

16 Comme dans les pays slaves, les oeuvres historiques byzantines qui circulaient dans les principautés roumaines servirent de modèles à l'historiographie naissante. Mais la seule présence de celles-ci, notamment dans des codex où elles précédaient les chroniques "nationales", témoigne également du processus d'acculturation des élites. Les chroniqueurs byzantins qui relataient l'"histoire du monde" depuis sa création étaient les mieux connus ${ }^{24}$; d'une façon analogue aux Slaves, la transmission de ces chroniques répondait probablement à un besoin d'intégration des Roumains dans l'histoire universelle $e^{25}$. Outre l'apport d'informations sur l'histoire du monde, ils offraient la possibilité d'une continuité avec l'histoire plus récente de leurs propres États ${ }^{26}$.

17 Certes, les premières oeuvres originales slavo-roumaines ne se distinguent guère en général de ces modèles, mais au moins deux d'entre elles, composées sous l'influence de la cour valaque de Neagoe Basarab, méritent une attention particulière: les Enseignements de Neagoe Basarab et la Vie de Niphon. Quel que soit le degré de participation du grand rhéteur du patriarcat de Constantinople Manuel de Corinthe à l'élaboration des Enseignements ${ }^{27}$, il n'en demeure pas moins que cette œuvre témoigne, sinon des réalités politiques, du moins de l'atmosphère culturelle qui régnait à la cour valaque à cette époque.

Ouvrage parénétique appartenant au genre des "miroirs des princes", les Enseignements se composent de deux parties. La première est destinée à apprendre à un jeune prince chrétien à «marcher dans les pas de Dieu », tant dans son comportement personnel de chrétien que dans le gouvernement qui lui est confié. Divers modèles monarchiques témoignent du destin des souverains "élus de Dieu" (tous des "empereurs" dans la tradition slavo-roumaine), soumis à l'implacable jugement divin ${ }^{28}$.

La seconde partie est constituée d'une succession d'enseignements, écrits probablement pour diverses occasions: il s'agit essentiellement de conseils moraux, concernant par exemple le comportement du prince à table, ou en présence d'ambassadeurs, ou même la conduite de la guerre et de la diplomatie. Tous répondent 
à un même besoin : fournir à la cour valaque un ouvrage didactique visant à éduquer, en premier lieu, un futur prince et, au-delà, tout chrétien désireux de suivre les vertus du "bon prince". Même si les circonstances de la rédaction (notamment la participation de Manuel de Corinthe) ne sont pas définitivement éclaircies, il est vraisemblable que l'oeuvre a été réellement commandée par Neagoe. Enfin, il est presque certain que la première partie a été créée en Valachie: conservée partiellement en slavon et intégralement dans la traduction roumaine du XVII ${ }^{\text {ème }}$ siècle, elle n'apparaît pas dans la version grecque.

\section{Identité orthodoxe}

Une littérature slavo-moldave s'est développée parallèlement. L'historiographie naissante de la Moldavie se présente comme une succession de chroniques dont la composition s'étale entre la fin du XV ème siècle et le troisième quart du XVI ${ }^{\text {ème }}$ siècle. Bien que leur circulation ait été d'une portée limitée, tout comme leurs sujets de préoccupation, principalement l'histoire des princes (de ce point de vue, les Enseignements font apparaître des préoccupations supérieures), les chroniques révèlent un sentiment d'appartenance à la communauté à la fois culturelle et religieuse de l'orthodoxie slavo-byzantine. Or, ce sentiment nous semble en partie exacerbé par les transformations politiques et spirituelles que connut l'Europe du sud-est, au détriment des États orthodoxes: en premier lieu la conquête ottomane, et, dans une moindre mesure, le prosélytisme catholique, ou encore la pénétration de la Réforme. Les menaces pesant sur la Moldavie orthodoxe se manifestent surtout dans les trois dernières chroniques moldaves du XVI ${ }^{\text {ème }}$ siècle $^{29}$.

Bien que l'époque soit un peu plus tardive, quelques précisions nous semblent nécessaires. Le moine Azarias, montrant comment le choix de l'entourage peut entraîner un prince vers le mauvais gouvernement, signale la présence autour du prince moldave d'origine grecque Jean Héraclide dit Despote (1561-1563), de luthériens "haïs de Dieu ${ }^{30}$ puis celle de Polonais catholiques auprès du faible Bogdan Lăpuşneanu (1568-1572) ${ }^{31}$. L'évêque Macaire déplore une guerre entre le voiévode moldave Bogdan l'Aveugle (1504-1517) et celui de Valachie Radu le Grand en ces termes : «les deux [princes] étant chrétiens, c'était une chose sans honneur " $^{32}$; or, ce type de regrets n'apparait pas dans le récit des conflits entre le même Bogdan et les Polonais. En 1529, à l'appel du roi hongrois Jean Zapolyai, Pierre Rareş de Moldavie (1527-1538 et 1541-1546) affronta des nobles hongrois rebelles en Transylvanie; Macaire précise que, malgré la supériorité militaire des Hongrois, les Moldaves finirent par l'emporter: " Mais les chrétiens ont appelé Dieu à l'aide et sont partis combattre

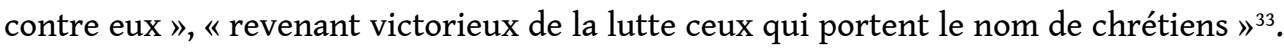
Cette insistance sur la victoire des "chrétiens" face à des adversaires catholiques nous incite à penser que le terme désigne ici les seuls orthodoxes, fidèles en la "vraie foi".

Si les chroniques antérieures contiennent moins d'informations, il n'en reste pas moins qu'une certaine affirmation de l'orthodoxie existait déjà. La chronique dite de Putna I mentionne le concile de l'Union des Églises à Florence (1438-1439), auquel la Moldavie fut représentée ${ }^{34}$. Évidemment, les subtilités dogmatiques des divisions entre chrétiens échappent au chroniqueur, mais l'Union est condamnée en des termes que n'aurait pas renié l'"opposition orthodoxe" contemporaine au concile: "l'empereur grec, le patriarche de Tsarigrad [Tsarigrad, "la ville du tsar" désigne communément 
Constantinople dans la littérature slavo-roumaine] et de nombreux métropolites se sont assemblés au concile de Florence, chez le pape de l'Ancienne Rome et ils ont été trompés par les Latins et plusieurs d'entre eux sont revenus avec les barbes rasées ${ }^{35}$. Ainsi, l'historiographie révèle une identité orthodoxe qui rapproche davantage les Roumains de leurs voisins sud-slaves que des catholiques.

\section{Solidarité orthodoxe?} soumise par les Ottomans. Dans l'historiographie slavo-roumaine de cette époque, les récits les plus explicites des luttes contre les Ottomans se trouvent dans les chroniques moldaves de la fin $\mathrm{du} X \mathrm{XV}^{\text {ème }}$ siècle et du début du suivant, qui relatent le long règne d'Étienne le Grand. Cette littérature aulique identifie clairement les Turcs comme principaux adversaires; ils sont désignés par un vocabulaire plus violent, principalement dans la Chronique anonyme moldave. Elle rapporte qu'Étienne le Grand a défait en 1475 les "païens" turcs, ce qui a réjoui l'ensemble des orthodoxes (pravoslavi) $^{36}$. L'année suivante, les Moldaves sont battus par les “Turcs maudits”, mais le chroniqueur porte aussi un jugement sévère à l'égard des "Valaques félons" accusés à juste titre d'avoir aidé les Ottomans et en quelque sorte trahi la solidarité qu'ils devaient à leurs frères ${ }^{37}$. Nous sommes là apparemment en présence d'un récit classique d'une guerre entre chrétiens et musulmans.

Cependant, d'une façon générale, les chroniques moldaves et les Enseignements insistent peu sur les aspects religieux du conflit. Il est vrai que les Roumains devaient craindre, plus qu'un prosélytisme musulman, des guerres où ils étaient en situation d'infériorité et, éventuellement, la disparition pure et simple de leurs États, à l'exemple des Slaves balkaniques ou de Byzance. Ainsi, même si les princes roumains ont surtout lutté contre les Ottomans, principale menace au cours de la période 1450-1520, il ne s'agissait pas pour autant d'une politique exclusive de défense de la chrétienté : à la fin de son règne, Étienne le Grand affronta surtout la Pologne. Alors qu'il avait sollicité de l'aide contre les Ottomans, dans une lettre adressée aux souverains chrétiens en 1475 (arguant de la situation de "porte de la chrétienté" de son pays) ${ }^{38}$, Étienne obtenait en 1497 un contingent de deux mille Turcs pour lutter contre une invasion polonaise, ce qui est noté de façon fort laconique par le chroniqueur anonyme ${ }^{39}$. De ce point de vue, ce sont des réalités politiques incontournables qui se sont imposées aux princes roumains, davantage que de perpétuels projets de croisades ${ }^{40}$.

Dans la culture roumaine, l'une des plus fortes représentations de la guerre contre les Ottomans repose sur l'utilisation de l'image de Constantin le Grand en lutte contre les païens. Sous Étienne le Grand fut copié, en 1474, le Panégyrique des empereurs Constantin et Hélène, écrit un siècle plus tôt par le patriarche Euthyme de Trnovo ${ }^{41}$. Un autre témoignage important est la scène de l'admirable chevauchée de Constantin (accompagné par une cohorte de saints militaires) peinte notamment dans l'église de PătrăuŢi en Moldavie en $1487^{42}$. Tous ces éléments montrent que l'on a recouru à une représentation hautement symbolique : le rappel de la victoire de Constantin par la Croix.

Cependant, d'autres luttes menées par le prince roumain élu de Dieu, y compris contre des chrétiens (présentés alors fréquemment comme les agresseurs), trouvent dans les chroniques princières une justification, même si l'image traditionnelle du souverain 
chrétien affrontant les païens pouvait être plus facilement utilisée. La Chronique anonyme est particulièrement sévère à l'égard du roi de Hongrie, Mathias Corvin, qui envahit la Moldavie en 1467 : Étienne le Grand y apparaît comme l'instrument de la vengeance divine contre l'orgueil démesuré du monarque ${ }^{43}$. Dans les Enseignements de Neagoe Basarab, nous trouvons bien une mise en garde contre les païens, mais il s'agit de conseils de prudence dans une situation d'infériorité manifeste, et l'esprit de croisade en est absent. En revanche, une "guerre juste" est définie dans les Enseignements : elle intervient après que tous les moyens pour sauvegarder la paix aient été épuisés. L'auteur, dans une ultime prière, déplore une guerre contre les "païens" qu'il aurait tout fait pour éviter : « mais nous, Seigneur, nous ne sommes pas heureux que se fasse cette guerre, selon ce que tu nous a ordonné, et nous ne voulons pas que du sang soit versé, ni souiller nos mains de sang humain $»^{44}$. Cette conception nous semble proche d'un pacifisme chrétien assez répandu à Byzance ${ }^{45}$.

En revanche, certaines chroniques reflètent une réaction face au nouveau contexte créé par la disparition des autres États orthodoxes de l'Europe du sud-est. La Chronique serbomoldave, probablement rédigée en Moldavie sous le règne de Bogdan l'Aveugle, est un court récit de l'histoire balkanique entre 1359 (fondation de la Moldavie) et 1512 (avènement du sultan Sélim II) ${ }^{46}$. La Moldavie est ainsi reliée à l'histoire d'États au passé plus prestigieux (Byzance, la Bulgarie et la Serbie), tout en apparaissant comme un État orthodoxe qui a survécu à la conquête. La chronique a une structure relativement symétrique : au début, les informations données concernent à la fois la naissance de la Moldavie et la menace croissante des Ottomans (à Gallipoli, en 1354). Ensuite sont relatées les étapes de la disparition des États balkaniques, "par la volonté de Dieu". À la fin, un face à face terrible semble annoncé par plusieurs signes célestes entre la Moldavie survivante (fondée elle aussi par la volonté de Dieu) et, à nouveau, les Ottomans : le sultan Sélim y est qualifié d"'empereur du mal" et d"“Antéchrist". La mission des Moldaves, voulue par Dieu, semble être une lutte contre les Ottomans, mais l'infériorité roumaine déplace ce combat sur un plan symbolique et eschatologique ${ }^{47}$. La présence de l'Hymne acathiste, magnifiquement exprimée dans la peinture extérieure d'églises moldaves de la première moitié du XVI ${ }^{\text {ème }}$ siècle (notamment à Moldovita, où le thème est associé à la superbe représentation du Siège de Constantinople) témoigne aussi de la croyance en une protection divine contre les païens ${ }^{48}$.

Cependant, l'image des sultans ottomans s'améliore progressivement dans les dernières chroniques moldaves du XVI ${ }^{\text {ème }}$ siècle ${ }^{49}$. La chronique d'Azarias montre bien l'omniprésence de l'autorité suprême impériale, celle des sultans de Constantinople (dont le "paganisme" n'est plus mis au premier plan). Bien qu'ayant préservé l'autonomie de leurs principautés, les Roumains partageaient en partie le destin des autres héritiers de la culture byzantine (la Russie mise à part) : l'influence politique dominante venait, à nouveau, de "Tsarigrad".

\section{L'héritage slavo-byzantin dans la tradition souveraine}

L'héritage slavo-byzantin est particulièrement visible dans la tradition souveraine. Des études ont mis en évidence la place de la tradition politique byzantine en Roumanie ${ }^{50}$, ainsi que son influence juridique et institutionnelle ${ }^{51}$. Dès le $\mathrm{XV}^{\text {ème }}$ siècle, des textes juridiques et canoniques byzantins (par exemple le Syntagmoc de Blastarès), ou même serbes (le Zakonik du tsar Étienne Dušan) ont été copiés dans les pays roumains. La 
réception du droit byzantin s'étend même au-delà du XVI ème siècle, puisqu'il influence encore les codes de lois du milieu du XVII ${ }^{\text {ème }}$ siècle.

L'examen de la diplomatique slavo-roumaine révèle une influence des usages byzantins ${ }^{52}$. L'abréviation Io qui précède le nom des princes dans les actes roumains est une contraction de Ioan (Jean), rappelant le prénom théophore hébraïque Iohanan, "celui qui est élu de Dieu" (pour régner). Cette formule, peut-être d'origine byzantine, était employée dans la diplomatique bulgare qui influença ensuite celle de la Valachie ${ }^{53}$. L'intermédiaire slave a été un relais indispensable : ainsi, le titre d'“autocrate" (en grec autokratôr, dans les textes en roumain du XVII ${ }^{\text {ème }}$ siècle singur stapânitor), présent surtout dans la titulature des princes valaques, apparaît plutôt dans sa forme slave (samodrajets). Il y a encore matière à discuter sur la signification de ce titre: "autocrate" est employé, dans les chroniques, avec un sens traditionnel de pouvoir personnel "autocéphale", et son utilisation dans les actes officiels ne s'est jamais limitée aux seuls cas d'association au trône, qui demeurent exceptionnels dans les pays roumains ${ }^{54}$.

31 Le droit divin est la clef de voûte de l'idéologie politique dans les principautés. S'agissant de souverains chrétiens, cela n'a évidemment rien d'exceptionnel ; toutefois, sa permanence au cours des siècles en dépit des dominations étrangères (sous la domination ottomane, les nominations des princes sont progressivement devenues le fait des sultans) montre l'enracinement d'une tradition ancienne, dont nous connaissons l'importance particulière à Byzance ${ }^{55}$.

Dans les chroniques, non seulement Dieu a placé le prince sur le trône, mais il l'assiste régulièrement au cours de son règne, notamment dans les victoires qu'il remporte contre tous ses ennemis, comme l'attestent plusieurs signes célestes. Dans les Enseignements, c'est de la même relation privilégiée du prince "oint de Dieu" (qui est en même temps un simple fidèle, pécheur comme le commun des mortels), avec Dieu dont il s'agit. Celle-ci est si forte que l'on pourrait employer le terme de "ministère" pour désigner la fonction princière, surtout comme modèle de comportement, de piété et d'orthodoxie pour les sujets. Comme pour d'autres souverains chrétiens, le droit divin remplit une fonction de légitimation, mais implique aussi de la part de l'élu le devoir de marcher dans les "pas de Dieu", de respecter scrupuleusement des obligations. La légitimité de droit divin, qui transparaît aussi dans des portraits princiers ${ }^{56}$, était un rempart contre les menaces de dislocation du pouvoir. Le système de succession ne garantissait pas la stabilité : il combinait l'hérédité et l'élection par les privilégiés. Cela permettait aux fils ou descendants d'un prince, légitimes ou non, de prétendre au pouvoir (ce qui n'est pas sans rappeler Byzance). Au cours du XVI ${ }^{\text {ème }}$ siècle, les princes ont, en outre, été soumis à la confirmation de leur pouvoir par le sultan. Pour cette raison, si on peut admettre que l'autocratie de droit divin conforte le pouvoir princier à l'intérieur du pays, il est plus difficile de partager l'idée qu'elle affirmerait aussi une indépendance "nationale" à l'extérieur ${ }^{57}$. Outre l'inadéquation du concept d'"indépendance" aux mentalités médiévales roumaines, cela ne semble guère compatible avec la permanence des dominations étrangères, ni avec la volonté des princes roumains de s'intégrer dans la communauté d'héritage byzantin, d'en recueillir et d'en perpétuer les traditions. 


\section{L'impérialisme dans la littérature} impériale byzantine subit des transformations en fonction des réalités du pays récepteur. Ce sont ces adaptations (par exemple l'évolution sémantique du vocabulaire politique), parfois même les continuités, qui sont au coeur du débat. Tous les modèles de ces princes sont monarchiques : rois bibliques et empereurs romains et byzantins sont autant d'“empereurs" (împăraŢi pour les Roumains) qui incarnent le pouvoir autocratique dans son essence même, tel qu'il a été confié à l'élu de Dieu. La donation d'un prince roumain est "impériale" par analogie lorsqu'elle imite celle des anciens souverains orthodoxes. Mais, en s'appuyant sur une idéologie qui faisait de lui un seigneur autocrate sous la dépendance, et sous la protection, du "Grand Seigneur" ottoman, le "grand empereur autocrate" de Constantinople, le prince roumain s'écartait des racines nobiliaires de son pouvoir.

\section{Le prince en tant qu'» élu »} celui des anciens basileis, lui-même héritier d'une tradition nourrie de références vétérotestamentaires, hellénistiques et romaines. Le prince élu de Dieu, s'il respecte les obligations divines, peut aspirer à devenir l'image de Dieu sur terre. Dans la Vie de Niphon, le prôtos Gabriel, après avoir cité les donations de Neagoe Basarab, décrit son règne par ces termes élogieux : «Et non seulement il fut bon pour les chrétiens, mais aussi pour les païens, et il fut pour tous un père miséricordieux, ressemblant au père céleste, qui fait étinceler son soleil et pleuvoir sur les bons et sur les méchants $\aleph^{62}$. Certes, l'auteur de ces lignes est sans doute un Grec, mais cette hagiographie écrite en relation avec la cour princière a été intégrée dans une grande compilation valaque de chroniques du XVII ${ }^{2}$ è siècle, la Chronique de la Valachie dite des Cantacuzènes ${ }^{63}$. De ce point de vue, certaines continuités dans la tradition souveraine méritent d'être soulignées.

Outre des qualités exceptionnelles (beauté, bonté, intelligence et sagesse, ...), le prince idéal se doit d'être un modèle pour tous, comme dans les Enseignements de Neagoe Basarab : il maitrise ses passions, fait preuve de retenue, y compris dans les moments les 
plus périlleux. Image de Dieu, il est le juge suprême et c'est même là son principal devoir. La philanthropie en est un autre, capital dans un système politique où le soutien des grandes familles nobiliaires était primordial pour s'assurer du trône et de son maintien au pouvoir. Les boyards sont demeurés un élément essentiel du système politique roumain et si les Enseignements insistent sur la légitimité de droit divin du prince, ils affirment aussi que le bon souverain est celui qui a su s'entourer de conseillers et gouverner en épargnant le sang de ses fidèles qui ont commis des fautes, sauf pour les cas les plus graves ${ }^{64}$.

\section{Conclusion}

Les Roumains ont bénéficié dès le XIV ème siècle de contacts privilégiées avec leur environnement slavo-byzantin. L'Église orthodoxe eut un rôle essentiel dans la transmission de la culture slavo-byzantine aux pays roumains (par les nominations de métropolites grecs, les contacts avec des moines slaves, les voyages, les échanges de manuscrits, etc.). La culture roumaine médiévale se développa aussi grâce à la protection des voiévodes, dans les cours princières ou dans les monastères qu'ils entretenaient. La symbiose de l'héritage slavo-byzantin et d'États apparus tardivement, alors en plein développement politique et économique, a donné naissance à une culture "slavo-roumaine"; parfois de simple imitation, elle fut aussi capable de produire des oeuvres originales, surtout à partir du début du XVI ème siècle.

Cette assimilation de l'héritage slavo-byzantin, ainsi que l'usage du slavon (la langue de l'Église, de la culture et de l'État) par des élites dont la langue vernaculaire est romane permet légitimement de parler d'acculturation. Aucun texte rédigé en roumain avant 1521 n'est parvenu jusqu'à nous, mais des mots roumains d'origine latine filtrent dans certains textes ${ }^{65}$. Bien qu'ayant conservé sa structure romane, la langue roumaine s'est enrichie d'apports slaves, tout comme au cours des siècles suivants, selon les influences culturelles, elle intègrera des mots grecs, turcs et français. Le roumain se répandit dans la seconde moitié du XVİ̀me siècle, même si le slavon conserva longtemps son prestige : la chancellerie princière, conservatrice, n'utilisa guère le roumain avant le XVII ${ }^{\text {ème }}$ siècle.

En dépit des liens étroits avec les rois catholiques de Hongrie et de Pologne, les voiévodes roumains adoptèrent plutôt des traditions politiques venus de Byzance et des États slaves. L'image des princes roumains est certes à rapprocher de celle des empereurs byzantins, bien qu'il ne puisse être question d'une transposition de l'universalité de la basileia. Dans les peintures, si le droit divin apparait, les voiévodes princes, en revanche, ne sont pas représentés nimbés: on est loin de "l'égal des apôtres" byzantin ou du culte dynastique des Serbes.

41 Toutefois, c'est dans des attitudes bien connues, comme le patronage des fondations orthodoxes, que les princes agirent le plus en héritiers des prédécesseus, les anciens "tsars" grecs et slaves. Nous avons souligné le rôle tout à fait caractéristique de Neagoe Basarab pour les donations à l'ensemble de l'Athos. Dans l'inscription de son église d'Arges, le prince se réclame d'une ancienne tradition politique, assumée depuis longtemps par les Valaques, liés aux dynasties bulgares et serbes ${ }^{66}$. D'ailleurs, la dignité "impériale" des voiévodes est également, rarement, évoquée dans des documents externes, telle la lettre de Manuel de Corinthe adressée au "basileus" Neagoe Basarab $(1519)^{67}$. 
fin, il ne faudrait pas sous-estimer l'importance de la position de ces princes chrétiens sous la domination ottomane. Une synthèse complète reste à faire sur le degré de souveraineté concédé par les "protecteurs" ottomans, qui laissaient à une date plus tardive (témoignages du XVIII ${ }^{\text {ème }}$ siècle) les princes (des beys dans la hiérarchie ottomane) nommés à Constantinople être couronnés dans l'église patriarcale, avec une cérémonie qui rappelait les derniers sacres impériaux. On peut aussi méditer sur les paroles attribuées à Radu le Grand dans la Vie de Niphon, lorsqu'il promet au patriarche disgrâcié d'obtenir l'autorisation du sultan de le faire venir en Valachie (« ne t'inquiète pas pour cela, c'est mon affaire ») : sans doute connaissait-il les limites réelles de son influence ${ }^{68}$.

\section{NOTES}

1. Voir notamment l'étude de Stănescu (Eugen), «Byzance et les Pays roumains aux IX-XVème siècles », Rapports du XIV ème congrès international des études byzantines, Bucarest, septembre 1971. Pour une analyse des diverses influences dans l'espace carpato-danubien, cf. Theodorescu (Răzvan), Bizanţ, Balcani, Occident, la începuturile culturii medievale româneşti (secolele X-XIV) (Byzance, les Balkans, l'Occident, aux débuts de la culture médiévale roumaine), Bucarest, 1974.

2. Nous donnerons, autant que possible dans cette étude limitée, quelques indications bibliographiques sur ces aspects.

3. Plusieurs synthèses présentent l'histoire médiévale de la Roumanie, mais elles sont souvent anciennes et en roumain. Parmi les synthèses classiques en français, citons celle de Iorga (Nicolae), Histoire des Roumains et de la Romanité orientale, Bucarest, 1937-1944, 11 vol. Un ouvrage réédité du même auteur a le mérite de replacer l'histoire roumaine dans un contexte plus large : La place des Roumains dans l'histoire universelle, Bucarest, 1980. Parmi les synthèses récentes: Constantinescu (Miron), Daicoviciu (Constantin), Pascu (Stefan), Histoire de la Roumanie, Roanne, 1970 ; Giurescu (Dinu), Histoire illustrée des Roumains, Bucarest, 1981.

4. Parmi les ouvrages généraux sur la littérature roumaine médiévale, celui de N. Cartojan demeure un classique, bien qu'un peu ancien : Cartojan (Nicolae), 1storia literaturii române vechi (Histoire de la littérature roumaine ancienne), Bucarest, 1980 (réédition); cf. aussi : Ciobanu (ştefan), Istoria literaturii române vechi, Chişinău, 1992 (réédition) ; Piru (Al), Istoria literaturii române, Perioada veche, vol. I, Bucarest, 1970.

5. L'oeuvre est conservée dans trois versions: grecque, slave et roumaine. Les plus anciennes (slave et grecque) datent $\mathrm{du} X V \mathrm{I}^{\mathrm{ème}}$ siècle tandis que la traduction roumaine du XVII ${ }^{\mathrm{ème}}$ siècle est la seule complète. L'édition la plus récente comprend la version roumaine et les fragments de la version slave: Zamfirescu (Dan), Moisil (Florica), Mihăilă (Gheorghe), éds., ÎnvăŢăturile lui Neagoe Basarab către fiul său Theodosie (Les Enseignements de Neagoe Basarab à son fils Théodose), Bucarest, 1970.

6. Le rôle de l'hésychasme dans la culture des Slaves balkaniques est rappelé par Obolensky (Dimitri), The Byzantine Commonwealth. Eastern Europe 500-1453, London, 1971, surtout pp. 301-307 ; voir aussi "Late Byzantine culture and the Slaves. A study of acculturation ", in The Byzantine Inherance of Eastern Europe, London, 1982, pp. 3-26, ainsi qu'une étude approfondie de l'activité culturelle à Trnovo et ses conséquences pour les pays roumains : Turdeanu (Emil), La littérature bulgare du XIV ème siècle et sa diffusion dans les pays roumains, Paris, 1957. 
7. Chihaia (Pavel), «Cu privire la ÎnvăŢături şi la câteva monumente din vremea lui Neagoe Basarab» (Autour des Enseignements et de quelques monuments de l'époque de Neagoe Basarab), Neagoe Basarab, 1512-1521. La 460 de ani de urcarea sa pe tronul Ţării Românești (Neagoe Basarab, 1512-1521. 460 ans depuis son avènement sur le trône de la Valachie), Bucarest, 1972, pp. 130-202.

8. Le débat est présenté précisément par Zamfirescu (Dan), Neagoe Basarab si ÎnvăŢăturile către fiul său Theodosie, problemele controversate (Neagoe Basarab et les Enseignements à son fils Théodose, les controverses), Bucarest, 1973. L'auteur attribue cette oeuvre au prince Neagoe lui même.

9. Des extraits traduits de cette oeuvre dans Laran (Michel), Saussay (Jean), éds., La Russie ancienne, IX-XVII ${ }^{\text {ème }}$ siècles, Paris, 1975, pp. 72-75.

10. Guilland (Rodolphe), «Les empereurs de Byzance et l'attrait du monastère ", Etudes byzantines, 1952.

11. Le moine Azarias, Cronicile slavo-române din secolele XV-XVI publicate de Ion Bogdan (Les chroniques slavo-roumaines des XV-XVI ${ }^{\text {ème }}$ siècles publiées par lon Bogdan), Bucarest : édition de P. P. Panaitescu, 1959, p. 147.

12. C'est l'un des aspects que nous étudions dans la préparation de notre thèse de doctorat qui porte sur le pouvoir souverain et ses bases idéologiques dans les principautés roumaines, à partir de l'étude des chroniques médiévales.

13. Turdeanu (Emil), op. cit., passim.

14. Le moine Nicodème de Tismana organisa les premiers monastères en Valachie. Sur sa place dans la culture roumaine et l'influence de l'hésychasme, cf. Turdeanu (Emil), op. cit., et «Les premiers écrivains religieux en Valachie: l'hégoumène Nicodème de Tismana et le moine Philothée », Revue des études roumaines, II, 1958 ; Lazarescu (E.), « Nicodim de la Tismana si rolul său în cultura veche românească » (Nicodème de Tismana et son rôle dans l'ancienne culture roumaine), Romanoslavica, 11 (1), 1965.

15. Mircea (L. R.), "Relations culturelles roumano-serbes au XVI ${ }^{\text {ème }}$ siècle ", Revue des Études Sud-Est européennes, 1 (3-4), 1963.

16. Iorga (Nicolae), Byzance après Byzance, Paris, 1992 (réédition).

17. Sur ces aspects, cf. Runciman (Steven), The Great Church in Captivity. A Study of the Patriarchate of Constantinople from the Eve of the Turkish Conquest to the Greek War of Independence, Cambridge, 1968.

18. Sur les visites patriarcales, cf. Popescu (N.), Patriarhii Tुarigradului înŢările române în veacul al XVI-lea (Les patriarches de Constantinople dans les pays roumains au XVI ${ }^{\text {ème }}$ siècle), Bucarest, 1914.

19. Le privilège de 1492 est publié dans la collection Panaitescu (P. P.), Mioc (Damaschin), éds., Documenta Romaaiae Historica, Ţara Românească, volume I (1247- 1500), Bucarest, 1966, pp. 377-380.

20. Sur les donations roumaines à l'Athos, voir notamment les travaux de Năsturel (Petre S.), «Le Mont Athos et ses premiers contacts avec la principauté de Valachie », Bulletin de l'Association Internationale d'Études du Sud-Est Européen, 1 (1-2), 1963, pp. 31-38; « Aperçu critique des rapports de la Valachie et du Mont Athos des origines au début du XVIème siècle », Revue des Études Sud-Est européennes, 2 (1-2), 1964 ; plus récemment la thèse : Le Mont Athos et les Roumains. Recherches sur leurs relations du milieu du XIV veme sièc1e à 1654, Rome, 1986.

21. Gabriel (prôtos), «ViaŢa şi traiul Sfinţiei Sale Părintelui nostru Nifon, patriarhul Ţarigradului » (La vie de Sa Sainteté notre père Niphon, le patriarche de Constantinople), in Mihăilă (Gheorghe), Zamfirescu (Dan), éds., Literatura româna veche, vol. 1, Bucarest, 1969, p. 91.

22. Ibid., pp. 76-77. La Vie de Niphon est conservée dans des versions grecque et roumaine. Sur leur succession, cf. Năsturel (Petre S.), « Recherches sur les rédactions gréco-roumaines de la Vie de saint Niphon II, patriarche de Constantinople », Revue des Études Sud-Est européennes, 5 (1-2), 1967.

23. Ibid., pp. 87-88. 
24. Une présentation des versions circulant dans les pays roumains: Mihăilă (Gheorghe), « Istoriografia română veche (sec. al XV-lea - începutul sec. al XVII-lea) în raport cu istoriografia bizantină şi slavă » (L'historiographie roumaine ancienne (XV-début du XVIII ${ }^{\text {ème }}$ siècle) en rapport avec l'historiographie byzantine et slave), Romanoslavica, 15, 1967. La chronique de Constantin Manassès, connue en Roumanie par sa traduction bulgare du XIVème siècle, a notamment influencé le style des chroniqueurs moldaves du XVI ${ }^{\text {ème }}$ siècle.

25. L'importance des chroniques byzantines chez les Slaves est rappelé par Obolensky (D.), op. cit., p. 330.

26. Nastase (Dumitru), "Unité et continuité dans le contenu de recueils manuscrits dits "Miscellanées" ", Cyrillomethodianum, 5, 1981. La présence dans les mêmes codex du XVI ème siècle de chroniques universelles byzantines et de chroniques moldaves établirait une "continuité impériale", permettant aux princes de revendiquer l'héritage des empereurs chrétiens.

27. La version grecque conservée a été écrite de sa main. Voir les arguments en faveur d'une paternité totale ou partielle de Manuel de Corinthe : Vranussis (L.), «Les Conseils attribués au Prince Neagoe (1512-1521) et le manuscrit autographe de leur auteur grec (ou la question homérique de la littérature slavo-roumaine enfin résolue !) ", Deuxième Congrès International des Études du Sud-Est européen, Programme, Athènes, 1970 ; Năsturel (Petre S.), « Remarques sur les versions grecque, slave et roumaine des "Enseignements du prince de Valachie Neagoe Basarab à son fils Théodose" ", Byzantinisch-Neugriechische Jahrbücher, 21, 1975. Cette dernière argumentation est adoptée aussi par Cazacu (Matei), "Slavon ou grec, traduction ou adaptation? Comment on composait un ouvrage parénétique en Valachie au début du XVI ème siècle (les Enseignements du prince Neagoe Basarab à son fils Théodose)", Traduction et traducteurs, Colloque international du CNRS, Paris, 26-28 mai 1986. La thèse opposée a été défendue surtout par Zamfirescu (Dan), Neagoe Basarab si ÎnvăŢăturile către fiul său Theodosie (op. cit.), et plus récemment dans « Între Neagoe Basarab şi Manuil de Corint. Răspuns d-lui Petre S. Năsturel » (Entre Neagoe Basarab et Manuel de Corinthe. Réponse à M. Petre S. Năsturel), Contribuţii la istoria literaturii române vechi (Contributions à l'histoire de la littérature roumaine ancienne), Bucarest, 1981.

28. La plupart de ces modèles sont empruntés à l'Ancien Testament (David, Salomon); la Vie de Constantin le Grand, composée au XIVème siècle par le patriarche bulgare Euthyme de Trnovo, est une autre source importante. Voir la note 41.

29. Les chroniques successives de l'évêque Macaire de Roman, de l'higoumène Euthyme et du moine Azarias racontent l'histoire de la Moldavie entre 1504 et 1574 ; le texte slave et la traduction roumaine ont été publiées par Panaitescu (P. P.), Cronicile slavo-române, Bucureşti, 1959.

30. Azarias, op cit., p. 143.

31. Ibid., p.148.

32. Macaire, in Cronicile slavo-române (op.cit.), p. 91.

33. Ibid., p. 96.

34. Sur l'histoire de l'Église moldave, cf. Păcurariu (Mircea), Istoria bisericii ortodoxe române (Histoire de l'Église orthodoxe roumaine), vol. I, Bucarest, 1992. Popescu (Emilian), «Compléments et rectifications à l'histoire de l'Église de Moldavie à la première moitié du XV ème siècle ", Christianitas daco-romana, Florilegium studiorum, Bucarest, 1994.

35. Chronique de Putna I, in Cronicile slavo-române (op.cit.), pp. 48-49.

36. Chronique anonyme moldave, "Récit depuis que, par la volonté de Dieu, est né le pays de Moldavie », in Cronicile slavo-române (op.cit.), p. 18.

37. Ibid.

38. La lettre est publiée dans l'anthologie Mihăilă (Gheorghe), Zamfirescu (Dan), éds., Literatura română veche, vol. 1, Bucarest, 1969, pp. 48-49.

39. Chronique anonyme, Cronicile slavo-române (op.cit.), p. 21. 
40. Des projets de croisades des puissances catholiques contre les Turcs prévoyaient cependant une participation des principautés roumaines. Par exemple les projets du pape Léon X (1517) rappelés par Neagoe (Manole), Neagoe Basarab, Bucarest, 1971, p. 66.

41. Étude et publication du texte par Mihăilă (Gheorghe), « Tradiţia literară constantiniană, de la Eusebiu al Cezareei şi Nichifor Calist Xanthopulos, Eftimiei al Tîrnovei şi domnii Ţărilor Române" (La tradition littéraire constantinienne, d'Eusèbe de Césarée et Nicéphore Caliste Xanthopoulos, d'Euthyme de Trnovo et les princes des pays roumains), Cultura si literatura română veche în context european, studii şi texte (La culture et la littérature roumaine ancienne dans le contexte européen, études et textes), Bucarest, 1979.

42. Drăgut (Vasile), Lupan (Petre), La peinture murale de la Moldavie (XV-XV ème siècles), Bucarest, 1983, pp. 13-14. Voir aussi la note 48.

43. Chronique anonyme, Cronicile slavo-române (op. cit.), p. 16.

44. Zamfirescu (Dan), Moisil (Florica), Mihăilă (Gheorghe), éds., op.cit., p. 279.

45. Des exemples dans Ducellier (Alain), Le drame de Byzance. Idéal et échec d'une société chrétienne, Paris, 1994 (réédition), pp. 177-181.

46. Publiée dans Cronicile slavo-române (op.cit.), pp. 189-193.

47. On trouve d'autres exemples dans les travaux de Dumitru Năstase, qui cherche à décrypter la signification cachée des chroniques; par exemple, Byzance d'Église et les pays roumains face à l'expansion ottomane dans les Balkans (1354-1432), thèse de doctorat, Paris I, 1976. Plus récemment, «Unité et continuité dans le contenu des recueils manuscrits» (art. cit.). La chronique serbomoldave y est analysée.

48. Voir les interprétations de Ulea (Sorin), « Origines et signification idéologique de la peinture extérieure des églises moldaves ", Revue Roumaine d'Histoire, 2 (1), 1963. L'ensemble de la peinture extérieure moldave est une gigantesque prière pour mobiliser le pays contre le danger ottoman.

49. Sur ce point, on consultera l'étude de Berza (Mihai), « Turcs, Empire ottoman et relations roumano-turques dans l'historiographie moldave des XV-XVII ème siècles », Revue des Etudes SudEst européennes, 10 (3), 1972.

50. Parmi les principales éludes, voir les communications sur le thème «Byzance et la Roumanie " des Actes du XIV ème congrès international d'études byzantines (Bucarest), 11, 1975, pp. 487-656. Voir aussi Elian (A.), "Moldova şi Bizanţul în secolul al XV-lea» (La Moldavie et Byzance au XV ème siècle), in Berza (M.), éd., Cultura moldovenească în timpul lui ştefan cel Mare (La culture moldave à l'époque d'Étienne le Grand), Bucarest, 1964. A. Pippidia écrit une synthèse, sur une période un peu plus tardive : Pippidi (Andrei), Tradiţia politică bizantină în Ţările române în secolele XVI-XVIII (La tradition politique byzantine dans les pays roumains aux XVI-XVIII ème siècles), Bucarest, 1983.

51. Georgescu (Valentin A.), BizanŢul şi instituŢiile româneşti până la mijlocul secolului al XVIII-lea (Byzance et les institutions roumaines jusqu'au milieu du XVIII ${ }^{\text {ème }}$ siècle), Bucarest, 1980 ; voir aussi « Byzance et les institutions roumaines jusqu'à la fin du XV ème siècle ", Rapports du XIVème Congrès international des études byzantines (op.cit.).

52. Bogdan (Damian P.), «L'influence byzantine dans les textes slavo-roumains », Actes du VI ème congrès international d'Études byzantines (Paris), I, 1948, pp. 383-384.

53. Vîrtosu (Emil), Titulatura domnilor şi asocierea la domnie în Ţara Românească şi Moldova (până în secolul al XVI-lea) (La titulature des princes et l'association au trône en Valachie et en Moldavie, jusqu'au XVI ème siècle), Bucarest, 1960, pp. 29-33 pour l'emploi dans la diplomatique bulgare et pp. 83-86 pour cette interprétation. Quel que soit le sens originel du prénom "Jean" dans la titulature des tsars bulgares, il semble bien que cette pratique ait été copiée par les chancelleries princières dans le seul but de distinguer les princes régnants et parfois leurs fils.

54. E. Vîrtosu (op.cit.) a évoqué l'existence possible d'un lien, du moins à l'origine, entre ce titre et l'association au trône, comme à Byzance, le "grand-voiévode" (prince titulaire) s'intitulant "autocrate". 
55. Guilland (R.), « Le droit divin à Byzance ", Études byzantines, 1952.

56. Les princes sont couronnés par des anges sur quelques fresques valaques du XVI ème siècle ; plusieurs exemples sont analysés par Dumitrescu (Carmen Laura), Pictura murală din Ţara Românească în veacul al XVI-lea (La peinture murale de Valachie au XVI ${ }^{\mathrm{ème}}$ siècle), Bucarest, 1978, passim.

57. C'est l'opinion de Georgescu (Valentin A.), op.cit.

58. Par exemple lors de son retour triomphal après la victoire sur les Ottomans en 1475 sous les acclamations de «Vive le tsar! », Chronique anonyme, Cronicile slavo-române, p. 18.

59. Ces inscriptions sont publiées dans Bălan (Constantin), éd., Inscripţii medievale şi din epoca modernă a Româaiei. Județul istoric Argeş (sec. XIV-1848) (Inscriptions du Moyen Âge et de l'époque moderne de la Roumanie. Le département historique d'Arges (XIVème siècle-1848), Bucarest, 1994 (réédition), pp. 203-212.

60. Cette dernière expression appartient à Năstase (Dumitru), «L'idée impériale dans les pays roumains et le "crypto-empire chrétien" sous la domination ottomane. État et importance du problème », Symmeikta, 1981 ; voir aussi Năsturel (Petre S.), « Considérations sur l'idée impériale chez les Roumains ", Byzantina, 5, 1973.

61. Georgescu (Valentin A.), op.cit. ; voir aussi «L'idée impériale byzantine et les réactions des réalités roumaines (XIV-XVIII ème siècles). Idéologie politique, structuration de l'État et du droit ", Byzantina, 3, 1971.

62. Gabriel (prôtos), art. cit., p. 92.

63. Grecescu (Constantin), Simonescu (Dan), éds., Istoria Ţarii RomâneşŢi (1290-1690), LetopiseŢul cantacuzinesc (Histoire de la Valachie (1290-1 690), La Chronique des Cantacuzènes), Bucarest, 1960.

64. Zamfirescu (Dan), Moisil (Florica), Mihăilă (Gheorghe), éds., op. cit., p. 255.

65. Le lecteur trouvera une liste des mots en langue roumaine rencontrés dans les textes slavoroumains, jusqu'au début $\mathrm{du} X \mathrm{XVI}^{\mathrm{ème}}$ siècle dans Mihăilă (Gheorghe), Dicţonar al limbii române vechi (sfărşitul sec. al X-lea- începutul sec. al XVI-lea) (Dictionnaire de la langue roumaine ancienne, fin du X-début du XVI ${ }^{\text {ème }}$ siècle), Bucarest, 1974.

66. Bălan (Constantin), éd., op.cit., pp. 208-210. Voir aussi l'analyse de Năsturel (Petre S.), « ÎnvăŢăturile lui Neagoe Basarab în lumina pisaniilor de pe biserica mănăstirii de la Argeș » (Les Enseignements de Neagoe Basarab à la lumière des inscriptions murales du monastère d'Arges), Mitropolia Olteniei, (1-2), 1960, (1-2).

67. Năsturel (Petre S.), « Manuil de Corinne către Neagoe Basarab », România literară, 2 (51), 1969, p. 13 ; voir aussi ; Năsturel (Petre S.), «Remarques sur les versions grecque, slave et roumaine » (art.cit.).

68. Gabriel (prôtos), art.cit., p. 74.

\section{RÉSUMÉS}

Les chroniques du XVème siècle en langue roumaine nous permettent d'appréhender la culture roumaine médiévale comme partie intégrante de son environnement slavo-byzantin. Elles ont notamment été transmises par les Slaves et constituent les prémices d'une littérature proprement moldave. L'orthodoxie partagée explique aussi en partie l'héritage byzantin en Moldavie et en Valachie. La religion a été vecteur de la solidarité envers l'ensemble des États 
orthodoxes conquis par les Ottomans, n'empêchant toutefois pas certaines alliances conjoncturelles pragmatiques de princes roumains avec les Ottomans, notamment contre les Polonais.

Medieval chronicles in Romanian language allow us to apprehend medieval Romanian culture as an integral part of its slavo-byzantine surrounding. They were handed down by the Slavs and represent the beginnings of a purely Moldovian literature. The shared orthodoxy explains, in part, byzantine inheritance in Valachia and Moldavia, which was the vector of solidarity toward orthodox states conquered by the Ottomans. This solidarity was not contradictory to some pragmatic alliances depending on circumstances of Romanian princes with the Ottomans, notably againts the Polish.

\section{AUTEUR}

\section{BENOÎT JOUDIOU}

B. Joudiou est agrégé d'histoire. 